\title{
Caracterização química e avaliação do rendimento em filés de caranha (Piaractus mesopotamicus)
}

\author{
Chemical characterization and evaluation of yield \\ in caranha fillets (Piaractus mesopotamicus)
}

Autores | Authors

Maria de Morais LIMA

Universidade Federal de Sergipe (UFS) Departamento de Tecnologia de Alimentos São Cristóvão/SE - Brasil e-mail:demoraislima@hotmail.com

\section{§ Pedro Ismael Cornejo MUJICA}

Universidade Federal do Tocantins (UFT) Laboratório de Tecnologia de Carnes e Derivados Av. NS-15 ALCNO 14, Centro CEP: $77020-210$ Palmas/TO - Brasil e-mail: pedroysmael@yahoo.com.br

Aldeíres Morais LIMA

Faculdade de Educação da Serra (FASE) Instituto Educacional Dados da Amazônia (IEDAM) Imperatriz/MA - Brasil e-mail: ahmlima@hotmail.com

Autor Correspondente / Corresponding Author Publicado / Published: dezembro/2012

\section{Resumo}

A caranha (Piaractus mesopotamicus) é uma espécie que se apresenta como uma importante fonte de proteína animal; possui grande aceitação entre os consumidores, em virtude de seu sabor agradável e da facilidade para a obtenção de filés. O objetivo deste estudo foi realizar a caracterização química e avaliar o rendimento em filés de caranha. Foram realizadas determinações de umidade, lipídios, proteínas e cinzas, segundo as metodologias recomendadas pelo Instituto Adolfo Lutz. A partir de peixe inteiro, foi avaliado o rendimento em peixe eviscerado, cabeça, costela, vísceras, escamas, filé com e sem pele/espinha e carcaça inteira. Concluiu-se que a caranha apresentou teores elevados de proteínas (17\%) e moderados teores de lipídios (5\%), apresentando um rendimento elevado para peixe eviscerado $(84,46 \%)$ e para filé com pele e espinha, $(30,17 \%)$, representando uma boa alternativa para o aproveitamento industrial. A carcaça inteira pode ser utilizada para a elaboração de polpa de peixe e produtos derivados.

Palavras-chave: Caranha; Caracterização química; Filés; Rendimento; Avaliação.

\section{Summary}

The caranha (Piaractus mesopotamicus) is a specie that presents itself as an important source of animal protein, and has wide acceptance among consumers due to its pleasant taste and ease for obtaining fillets. The aim of this study was to chemical characterization and evaluate the yield of caranha fillets. Were subjected to moisture, lipid, protein and ash according to methods recommended by the Instituto Adolfo Lutz. From whole fish, we measured the yield of gutted fish, head, ribs, viscera, scales, and fillet with and without skin/spine and whole carcass. It was concluded that the caranha showed high levels of protein (17\%) and moderate levels of lipids (5\%), with a high yield for gutted fish (84.46\%) and fillet with skin and spine (30.17\%) representing a good alternative for industrial use. The whole carcass can be used to produce minced fish and derived products.

Key words: Caranha; Chemical characterization; Fillets; Yield; Evaluation. 


\section{Introdução}

Com um dos maiores espelhos de água do mundo, o Brasil tem potencial para se tornar um dos grandes produtores mundiais de pescado cultivado. A piscicultura pode contribuir para a produção pesqueira nacional, a geração de emprego, a renda e o abastecimento alimentar, tornando-se uma atividade com grandes perspectivas de crescimento.

A piscicultura no Estado do Tocantins apresenta-se como uma atividade estratégica na produção de alimentos, em função da grande extensão de corpos hídricos e da abundância de recursos naturais favoráveis para o cultivo de espécies de grande valor comercial, como tambaqui, caranha e pirarucu, entre outros.

Os pescados são conhecidos pelo elevado valor nutricional; dentre seus constituintes, destaca-se o alto teor de proteínas e sais minerais (cálcio, fósforo e ferro), além da gordura, que é considerada uma das maiores fontes de ácidos graxos da família ômega-3 (n-3). Estes componentes destacam-se pela sua elevada importância fisiológica e nutricional (OGAWA e MAIA, 1999).

A caranha (Piaractus mesopotamicus) é uma espécie que se adaptou ao cativeiro e possui grande aceitação entre a população, em razão de seu excelente sabor, consistência, coloração branca da carne e facilidade para a obtenção de filés. Enfim, é uma das espécies com potencial para o crescimento da aquicultura nacional.

Pesquisas com rendimento de carcaça de peixes para se obter maior eficiência nos sistemas de produção buscam aumento no rendimento de cortes nobres e mais valorizados pelo mercado consumidor. O valor nutritivo e os preços dos peixes dependem da composição química, da textura da carne, do rendimento e de fatores relacionados aos métodos de captura e beneficiamento.

O processamento industrial de pescados fornece muito mais do que alimentos nutritivos, na medida em que gera também uma grande quantidade de resíduos, os quais são quase totalmente desperdiçados. Em uma estimativa bastante otimista da captura mundial de pescado, citada por Morales-Ulloa e Oetterer (1995), acredita-se que $72 \%$ do que é desembarcado é utilizado no mercado como peixe fresco, congelado, enlatado ou curado. Os outros $28 \%$ são diretamente processados como farinha para ração animal ou ainda despejados no meio ambiente, sem praticamente nenhum tratamento. Além disso, o pescado que é destinado à comercialização e à industrialização para consumo humano rende de 25 a 70\% da matéria-prima como produto comestível. Assim, as partes não aproveitáveis somam 20 milhões de toneladas anuais, sendo essa sobra igual ao peso do pescado inteiro utilizado para fabricação de farinha; isso mostra que mais de dois terços dos desembarques não são utilizados na alimentação humana, embora seu valor nutricional seja comparado à parte comercializada.

Os resíduos sólidos do beneficiamento do pescado são destinados principalmente à alimentação animal, mas também podem ser aproveitados para a produção de alimentos para consumo humano. O valor nutricional desses resíduos, ricos em proteínas e em ácidos graxos da série ômega-3, incentiva o desenvolvimento de produtos para a alimentação humana (MIRANDA et al., 2003).

Os resíduos da indústria de pescado apresentam uma composição rica em compostos orgânicos e inorgânicos, o que gera preocupação relativa aos potenciais impactos ambientais negativos decorrentes da disposição deste material diretamente no ambiente ou oferecido in natura aos peixes cultivados (HENRY-SILVA e CAMARGO, 2002; SEIBEL e SOARES, 2003).

O pescado representa uma fonte de diversos componentes com significativo valor nutricional, como proteínas e minerais, além de ser a maior reserva de ácidos graxos polinsaturados, especialmente da série ômega-3, aos quais são atribuídos importantes benefícios ao organismo humano (LUZIA et al., 2003). Entretanto, o Brasil apresenta um dos mais baixos índices de consumo de pescado, de 9,75 kg per capita em 2010 (BRASIL, 2010), bem abaixo da média mundial, de 17,0 kg per capita (FAO, 2010).

Este fato se explica não só por problemas na distribuição e na comercialização, mas também, muitas vezes, pela falta do hábito de consumo, gerado, em parte, pela ausência de praticidade no preparo. Além disto, a ingestão deste alimento está sujeita a diferentes influências, como o fator socioeconômico dos consumidores e a disponibilidade de pescado com qualidade adequada (TRONDSEN et al., 2003).

Dessa forma, sente-se a necessidade de procurar novas alternativas para a utilização desta matériaprima, podendo-se, com isto, transformá-la em produtos aceitáveis pela população, conduzindo a um maior consumo.

O consumo mundial de pescado tem apresentado taxas de crescimento elevadas nos últimos anos, no momento em que fatores, como a preocupação com alimentação de qualidade e frequentes problemas de risco alimentar, influenciam positivamente este comportamento. A preocupação em consumir alimentos mais saudáveis, que apresentem baixos teores de gordura, livres de colesterol e produzidos sem o uso de produtos químicos, tem contribuído para um incremento na demanda do consumo de pescado. Nas últimas décadas, o consumo regular de pescado recebeu atenção especial dos consumidores, visando a obter os benefícios que o mesmo traz à saúde (MICHELS e PROCHMANN, 2002). 
No processamento da caranha, é importante destacar que o peixe gera grande quantidade de resíduos e que estes podem ser aproveitados na fabricação de outros produtos alimentícios. Segundo Brushi (2001), muitas tecnologias têm surgido para possíveis utilizações dos resíduos como fontes alimentares, transformando-os em produtos nutritivos e com boa aceitação no mercado; é o caso, por exemplo, do surimi, que pode ser obtido através da carne que fica aderida à espinha dorsal do pescado no processo de filetagem, além de outros produtos, como patês, bolinhos e fishburguers.

Conhecer a composição centesimal ou a composição química de um alimento é um fator essencial para tomadas de decisões de caráter dietário. No que diz respeito à elaboração e à conservação de produtos alimentícios, estas informações são importantes, pois fornecem subsídios à padronização da produção, por meio do acompanhamento dos processos industriais e da escolha de equipamentos a serem utilizados.

O beneficiamento de pescado é um dos principais gargalos da cadeia produtiva da piscicultura, fazendo com que os produtores vendam seus produtos in natura, às vezes sem qualidade e sem passar por um processo de beneficiamento. Neste contexto, a técnica de filetagem torna-se uma alternativa de beneficiamento, além de promover uma agregação de valor ao pescado. Por não existir um padrão desse processamento, há divergência em relação ao melhor método a ser empregado, ou seja, qual método proporciona o maior rendimento de filé, a maior facilidade operacional e o menor tempo de processamento.

Considerando-se a importância de se conhecer a composição química, o valor nutritivo e o potencial de utilização da carne e dos resíduos provenientes da filetagem da caranha, é necessário determinar a caracterização química e o rendimento em filés, bem como conhecer a porcentagem de resíduos gerados na filetagem desta espécie. Neste contexto, o objetivo deste estudo foi determinar a composição química e avaliar o rendimento em filés de caranha (Piaractus mesopotamicus).

\section{Material e métodos}

\subsection{Material}

\subsubsection{Matéria-prima}

A caranha (Piaractus mesopotamicus) foi proveniente de criatório localizado em Porto Nacional-TO; após a despesca, os peixes foram lavados com água clorada para retirada do muco superficial e outras impurezas. A seguir, foram acondicionados em caixa térmica com gelo e transportados até o Laboratório de Tecnologia de Carnes do Curso de Engenharia de Alimentos da Universidade Federal do Tocantins, para a realização do presente estudo.

\subsection{Métodos}

\subsubsection{Caracterização química}

Foram realizadas determinações de: umidade, pelo método de secagem em estufa a $105^{\circ} \mathrm{C}$ até peso constante; lipídios, pelo método de Soxhlet, usando-se hexano como solvente extrator; proteínas, pelo método micro-Kjeldahl $(\mathrm{N} \times 6,25)$, e cinzas, pelo método de incineração em mufla a $550{ }^{\circ} \mathrm{C}$ até peso constante, segundo as metodologias recomendadas pelo Instituto Adolfo Lutz (IAL, 2007). As análises foram realizadas em triplicata, a partir de um homogeneizado de $240 \mathrm{~g}$ de filés.

\subsubsection{Avaliação do rendimento em filés}

Foram utilizados 15 exemplares de caranha, com um comprimento médio de $32,8 \pm 1,88 \mathrm{~cm}$, com peso médio de $1.320,3 \pm 75,22 \mathrm{~g}$. A partir do peixe inteiro, foi avaliado o rendimento em peixe eviscerado, cabeça, filé (músculos epaxiais retirados no sentido longitudinal) com e sem espinha, costela, vísceras, escamas e carcaça inteira.

\section{Resultados e discussão}

\subsection{Caracterização química}

$\mathrm{Na}$ Tabela 1, são apresentados os resultados da caracterização química da caranha (Piaractus mesopotamicus).

A composição química de um pescado é extremamente variável e depende de fatores relacionados à espécie e ao ambiente, além da época do ano, da quantidade e da qualidade do alimento consumido, do estágio de maturação sexual, da idade e da parte do corpo analisada.

Segundo Ogawa e Maia (1999), o músculo de pescado pode conter de 60 a $85 \%$ de umidade, aproximadamente $20 \%$ de proteínas, de 1 a $2 \%$ de cinzas, de 0,3 a 1,0\% de carboidratos e de 0,6 a 36\% de lipídios. Este último componente apresenta uma maior variação

Tabela 1. Caracterização química da caranha (Piaractus mesopotamicus)*.

\begin{tabular}{lr}
\multicolumn{1}{c}{ Determinações } & \multicolumn{1}{c}{$(\mathbf{\%})$} \\
\hline Umidade & $76,86 \pm 0,82$ \\
Lipídios & $5,00 \pm 0,32$ \\
Proteínas & $17,00 \pm 0,18$ \\
Cinzas & $0,92 \pm 0,07$ \\
\hline
\end{tabular}

*Valores médios de três determinações. 
em função do tipo de músculo, do sexo, da idade, da época do ano, do habitat e da dieta, entre outros fatores. Estes valores são compatíveis com os obtidos no presente estudo para a composição química da caranha.

Contreras-Guzmán (1994) cita que a fração de cinzas em peixes de água doce apresenta teores entre 0,90 e 3,39\%. Este valor é concordante com o teor de cinzas encontrado no presente trabalho para caranha. A carne de pescado é considerada uma fonte valiosa de cálcio e fósforo, particularmente; apresenta também quantidades razoáveis de sódio, potássio, manganês, cobre, cobalto, zinco, ferro e iodo.

Mujica e Lima (2011), estudando a composição química de tambaqui (Colossoma macropomum), encontraram teores de $77,75 \%$ de umidade, $1,60 \%$ de lipídios, $19,75 \%$ de proteínas e $0,70 \%$ de cinzas. Os valores obtidos neste estudo estão próximos aos reportados pelos referidos autores.

Garcia-Torchelsen et al. (2011), estudando a composição centesimal do músculo de anchoita (Engraulis anchoita), encontraram teores de $77,88 \%$ de umidade, $16,46 \%$ de proteínas, $2,06 \%$ de cinzas e $3,60 \%$ de lipídios. Os valores encontrados neste trabalho também são próximos aos referidos teores.

Lima et al. (2012) avaliaram a composição química de vermelha (Lutjanus $s p$ ), encontrando a seguinte composição centesimal: $78,53 \%$ de umidade, 0,52\% de lipídios, $17,94 \%$ de proteínas e 1,26\% de cinzas. Os valores observados no presente estudo são similares aos relatados por esses autores

Mujica et al. (2011), avaliando a composição centesimal de filés de matrinchã (Brycon cephalus), encontraram teores de $79,93 \%$ de umidade, $2,89 \%$ de lipídios, $16,40 \%$ de proteínas e $0,76 \%$ de cinzas. Os valores obtidos no presente trabalho são divergentes com os reportados por esses autores.

Lima et al. (2011) avaliaram a composição química de piau (Leporinus obtusidens), encontrando teores de $71,3 \%$ de umidade, $8,43 \%$ de lipídios, $19,5 \%$ de proteínas e $0,70 \%$ de cinzas. Os valores observados no presente estudo são discordantes com os relatados pelos autores referidos.

Caula et al. (2008), avaliando a composição química de várias espécies, encontraram, para tilápia, $81,7 \%$ de umidade, $2,2 \%$ de lipídios, $18,2 \%$ de proteínas e $1,2 \%$ de cinzas, e, para curimatã, $77,5 \%$ de umidade, 4,2\% de lipídios, $19,7 \%$ de proteínas e 1,1\% de cinzas. Os valores obtidos no presente trabalho são discordantes com os observados para tilápia, mas estão próximos aos reportados para curimatã, no referido estudo.

De acordo com Pigott e Tucker (1990), a classificação de pescados segundo o teor de gordura está baseada na seguinte relação: menor que $2 \%$ de lipídios, é um pescado de baixo conteúdo de gordura; entre 2 e $5 \%$, é um pescado moderado em conteúdo de gordura, e maiores que $5 \%$, é considerado um pescado com alto conteúdo de gordura. De acordo com os resultados obtidos neste estudo, a caranha pode ser classificada como um pescado com moderado teor de gordura.

Contreras-Guzmán (1994) considera que inúmeros fatores podem influenciar a composição química dos peixes, sendo alguns de natureza intrínseca, tais como fatores genéticos, morfológicos (tamanho e forma) e fisiológicos (migração e desenvolvimento gonadal). Fatores exógenos, tais como clima, estação do ano, abundância e tipo de alimentação também podem afetar a composição corporal.

\subsection{Avaliação do rendimento em filés}

Verificou-se um rendimento de $84,46 \%$ (peixe eviscerado), 20,80\% (cabeça), 30,17\% (filé com pele e espinha), $25,24 \%$ (filé sem pele e espinha), 17,51\% (costela), 3,57\% (escamas), 15,54\% (vísceras) e 10,86\% (carcaça inteira). Os resíduos representados pela cabeça e a carcaça inteira corresponderam, em média, a 32\% do total do pescado, o que salienta a importância de seu aproveitamento na elaboração de caldos e sopas. 0 rendimento de $84,46 \%$ para peixe eviscerado e de $25,24 \%$ para filé sem pele e espinha é considerado elevado para fins de aproveitamento industrial.

Mujica e Lima (2011), estudando o rendimento em filés de tambaqui (Colossoma macropomum), encontraram um rendimento de $87,95 \%$ (peixe eviscerado), $24,41 \%$ (cabeça), 32,33\% (filé com pele/espinha), 27,76\% (filé sem pele/espinha), 16,27\% (costela), 11,07\% (carcaça), 2,37\% (escamas) e 12,05\% (vísceras). Os valores obtidos no presente estudo são concordantes com os observados por esses autores.

Lima et al. (2012), avaliando o rendimento de vermelha (Lutjanus sp), determinaram os seguintes valores: 94,29\% (peixe eviscerado), 28,70\% (cabeça), 32,03\% (filé), 9,55\% (costela), 4,67\% (pele/escamas), $5,71 \%$ (vísceras) e $12,77 \%$ (carcaça inteira). Os valores encontrados no presente trabalho são divergentes destes relatados.

Mujica et al. (2011), em seu estudo de caracterização química e avaliação do rendimento em filés de matrinchã (Brycon cephalus), observaram um rendimento de $81,45 \%$ (peixe eviscerado), 11,72\% (cabeça), 33,79\% (filé com pele), 32,4\% (filé sem pele) e 43,79\% (carcaça inteira). Os valores obtidos no presente estudo são discordantes com estes reportados.

Lima et al. (2011), avaliando o rendimento de piau (Leporinus obtusidens), determinaram um rendimento de $94,25 \%$ (peixe eviscerado), 14,72\% (cabeça), 37,8\% 
(filé com pele), 32,3\% (filé sem pele) e 36,5\% (carcaça inteira). Os valores observados no presente trabalho são divergentes com os ora relatados.

Souza (2002) determinou o rendimento em filés de tilápia (Oreochromis niloticus) em torno de 34,6 a $36,6 \%$, porém encontrou diferenças significativas quanto aos métodos de filetagem usados. O melhor método de filetagem foi o que retirou a pele do peixe inteiro e depois removeu o filé. Os valores obtidos no presente estudo são discordantes com os reportados pelo referido autor.

O rendimento em filés, além da eficiência das máquinas filetadoras ou da destreza manual do operário, depende de algumas características intrínsecas à matéria-prima, ou seja, da forma anatômica do corpo, do tamanho da cabeça e dos pesos dos resíduos (vísceras, pele e nadadeiras) (CONTRERAS-GUZMÁN, 1994). Quanto à forma anatômica do corpo, EYO (1993) realizou um estudo com dez espécies de peixes e constatou que o rendimento é um reflexo da estrutura anatômica, ou seja, peixes com cabeça grande em relação ao corpo apresentam um menor rendimento na filetagem, quando comparados aos de cabeça pequena em relação ao corpo.

De acordo com Sikorski (1994), a cabeça representa uma elevada porcentagem do peso total do peixe, variando de $21,7 \%$ a $29,02 \%$.

Para a indústria, é importante a carcaça de peixe, principalmente quanto à preparação do produto, aos tipos de cortes, à produção e ao rendimento em filés; enfim, em relação aos processos, que vão desde o abate até a industrialização e a apresentação do produto ao consumidor. Para o produtor, somente interessa o peso do peixe a ser entregue à indústria (BRUSHI, 2001).

No Brasil, o aproveitamento dos resíduos de pescado é pequeno, sendo que a maioria destes resíduos é descartada, causando, por consequência, um sério problema ambiental. As indústrias de beneficiamento de pescado geram grandes quantidades de resíduos, em razão, principalmente, da falta de reconhecimento deste recurso como matéria-prima e fonte para outros produtos (PESSATTI, 2001).

As cabeças, escamas, peles, vísceras e carcaças (esqueleto com carne aderida) são os principais resíduos do processamento de pescado. Dependendo da espécie de peixe processada e do produto final obtido pelo frigorífico, estes resíduos podem representar algo entre 8 e 16\% (no caso do pescado eviscerado), e entre 60 e $72 \%$, na produção de filés sem pele (KUBITZA, 2006).

A proporção de carcaça inteira, representada por ossos e espinhas com carne remanescente, pode ser considerada elevada, podendo ser utilizada para a elaboração de polpa de pescado e produtos derivados do aproveitamento desta.
O uso de tecnologias para o aproveitamento dos resíduos do beneficiamento do pescado, no desenvolvimento de produtos para a alimentação humana, aumenta a capacidade da indústria da pesca de responder não só à demanda por produtos diferenciados, mas também à tendência da busca por alimentos saudáveis e com alto valor nutritivo, suprindo as necessidades nutricionais - em especial, de proteínas animais, pelos setores mais carentes da população, por um preço acessível (MIRANDA et al., 2003).

\section{Conclusão}

A caranha apresentou teores elevados de proteínas (17\%) e moderados teores de lipídios (5\%). Verificou-se um rendimento elevado para peixe eviscerado $(84,46 \%)$ e filé com pele e espinha $(30,17 \%)$, representando uma boa alternativa para o aproveitamento industrial. Os resíduos gerados do processo de filetagem da caranha apresentam grande potencial de aproveitamento e podem ser utilizados para a elaboração de diversos produtos para consumo humano, como carne mecanicamente separada, surimi, produtos reestruturados, concentrado proteico e óleo, dentre outros.

\section{Referências}

BRASIL. Ministério da Pesca e Aqüicultura - MPA. Boletim Estatístico da Pesca e Aquicultura. Brasília: MPA, 2010. Disponível em: <http://www.mpa.gov.br/mpa/>. Acesso em: 25 abr. 2012.

BRUSHI, F. L. F. Rendimento, Composição Química e Perfil de Ácidos Graxos de Pescados e seus Resíduos: uma Comparação. 2001. 65 f. Monografia (Graduação em Oceanografia)-Universidade do Vale do Itajaí, Itajaí, 2001.

CAULA, F. C. B.; OLIVEIRA, M. P.; MAIA, E. L. Teor de colesterol e composição centesimal de algumas espécies de peixes do Estado do Ceará. Ciência e Tecnologia de Alimentos, Campinas, v. 28, n. 4, p. 157-163, out./dez. 2008. http://dx.doi. org/10.1590/S0101-20612008000400031

CONTRERAS-GUZMÁN, E. S. Bioquímica de Pescados e Derivados. Jaboticabal: FUNEP, 1994.

EYO, A. A. Carcass composition and filleting yield of ten fish species from Kainji Lake: proceedings of the FAO expert consultation on fish technology in Africa. FAO Fishers Report, Rome, n. 467, p. 173-175, 1993.

FOOD AND AGRICULTURE ORGANIZATION OF THE UNITED NATIONS - FAO. The State of World Fisheries and Aquaculture 2010. Rome: FAO, 2010. Disponível em: <http:// http://www.fao.org/docrep/013/i1820e/i1820e.pdf>. Acesso em: 08 maio 2012.

GARCIA-TORCHELSEN, L.; JACOB-LOPES, E.; QUEIRO, M. I. Avaliação funcional de bases proteicas desidratadas de 
Caracterização química e avaliação do rendimento em filés de caranha (Piaractus mesopotamicus) LIMA, M. M. et al.

anchoita (Engraulis anchoita). Brazilian Journal of Food Technology, Campinas, v. 14, n. 4, p. 283-293, out./dez. 2011. http://dx.doi.org/10.4260/BJFT2011140400034

HENRY-SILVA, G. G. H.; CAMARGO, A. F. M. Valor nutritivo de macrófitas aquáticas flutuantes (Eichhornia crassipes, Pistia stratiotes e Salvinia molesta) utilizadas no tratamento de efluentes de aqüicultura. Acta Scientiarum, Maringá, v. 24, n. 2, p. 519-526, 2002.

INSTITUTO ADOLFO LUTZ - IAL. Normas Analíticas do Instituto Adolfo Lutz - Métodos Físicos e Químicos. 3. ed. São Paulo: IAL, 2007. v. 1, 533 p.

KUBITZA, F. Aproveitamento dos subprodutos do processamento de pescados. Panorama da Aqüicultura, Rio de Janeiro, v. 16, n. 94, p. 23-29, 2006.

LIMA, M. M.; NUNES, M. L.; MUJICA, P. I. C.; LIMA, A. M.; SANTOS, J. A. B.; SILVA, G. F. Caracterização química e avaliação do rendimento em filés de vermelha (Lutjanus $s p$ ). In: FEIRA NACIONAL DO CAMARÃO, 9., 2012, Natal. Anais... Natal: FENANCAM, 2012. 1 CD-ROM.

LIMA, M. M.; MUJICA, P. Y. C.; LIMA, A. M.; SANTOS, Y. L.; LEITE, M. S.; BORGES, R. G. Caracterização Química e Avaliação do Rendimento em Filés de Piau (Leporinus obtusidens). In: SIMPÓSIO DE CIÊNCIA E TECNOLOGIA DE ALIMENTOS, 3., CONGRESSO DO INSTITUTO NACIONAL DE FRUTAS TROPICAIS, 2., SEMINÁRIO DE CIÊNCIA DE ALIMENTOS, 4., 2011, Recife. Anais... Recife: SBCTA, 2011. 1 CD-ROM.

LUZIA, L. A.; SAMPAIO, G. R.; CASTELLUCCI, C. M. N.; TORRES, E. A. F. S. The influence of season on the lipid profiles of five commercially important species of Brazilian fish. Food Chemistry, London, v. 83, n. 1, p. 93-97, 2003. http://dx.doi. org/10.1016/S0308-8146(03)00054-2

MICHELS, I. L.; PROCHMANN, A. M. Estudo das Cadeias Produtivas de Mato Grosso do Sul: Piscicultura. Campo Grande: UFMS; 2002.

MIRANDA, F. F.; PORTO, M. R. A.; PACHECO, R. S. Processo tecnológico destinado à obtenção de flocos de corvina (Micropogon furnieri). In: CONGRESSO DE INICIAÇÃO CIENTífICA, 12., 2003, Pelotas. Anais... Pelotas: UFPel, 2003. CD-ROM.
MORALES-ULLOA, D. F.; OETTERER, M. Bioconversão de resíduos da indústria pesqueira. Ciência e Tecnologia de Alimentos, Campinas, v. 15, n. 3, p. 206-214, 1995.

MUJICA, P. I. C.; LIMA, M. M. Caracterização físicoquímica e avaliação do rendimento em filés de tambaqui (Colossoma macropomum). In: CONGRESSO SERGIPANO DE CIÊNCIAS, 2011, Aracaju. Anais... Aracaju: Associação Sergipana de Ciência, 2011. 1 CD-ROM.

MUJICA, P. Y. C.; LIMA, M. M.; SOUSA, J. R.; LEITE, M. S.; CORNÉLIO, T. F.; LEITE, Y. S. Caracterização química e avaliação do rendimento em filés de matrinchã (brycon cephalus). In: CONGRESSO BRASILEIRO DE CIÊNCIA E TECNOLOGIA DE CARNES, 6., 2011, São Pedro. Anais... São Pedro: ITAL, 2011. 1 CD-ROM.

OGAWA, M.; MAIA, E. L. Química do pescado. In: OGAWA, M.; MAIA, E. L. Manual de Pesca: Ciência e Tecnologia do Pescado. São Paulo: Varela, 1999. v. 1, cap. 4, p. 27-71.

PESSATTI, M. L. Aproveitamento dos Subprodutos do Pescado: Meta 11. Itajaí: Universidade do Vale do Itajaí, 2001. Relatório final de ações prioritárias ao desenvolvimento da pesca e aqüicultura no sul do Brasil, convênio Ministério da Agricultura, Pecuária e Abastecimento - MAPA.

PIGOT, G.; TUCKER, B. Sea Food Effects of Technology on Nutrition. New York: Marcel Dekker, 1990. 390 p.

SEIBEL, N. F.; SOARES, L. A. S. Produção de silagem química com resíduos de pescado marinho. Brazilian Journal of Food Technology, Campinas, v. 6, n. 2, p. 333-337, 2003.

SIKORSKI, Z. E. Tecnologia de los Productos del Mar: Recursos, Composicion Nutritiva y Conservacion. Zaragoza: Acribia, 1994. 329 p.

SOUZA, M. L. R. Comparação de seis métodos de filetagem, em relação ao rendimento de filé e de subprodutos do processamento da Tilápia-do-Nilo (Oreochromis niloticus). Revista Brasileira de Zootecnia, Viçosa, v. 31, n. 3, p. 1076-1084, 2002. http:// dx.doi.org/10.1590/S1516-35982002000500003

TRONDSEN, T.; SCHOLDERER, J.; LUND, E.; EGGEN, A. E. Perceived barriers to consumption of fish among Norwegian women. Appetite, London, v. 41, n. 3, p. 301-314, 2003. http:// dx.doi.org/10.1016/S0195-6663(03)00108-9 